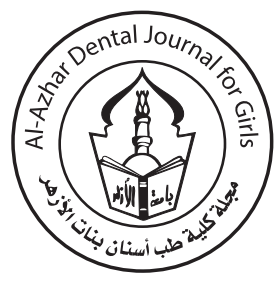

\title{
Evaluation of Dental Implant Stability: A comparative Study of Tapered vs Cylindrical Implants
}

\author{
Doaa A. Alghafour ${ }^{1 *}$, Eatemad A. Shoreibah ${ }^{2}$, Mai S. Attia ${ }^{3}$
}

Codex : 14/21.10

azhardentj@azhar.edu.eg

http://adjg.journals.ekb.eg

DOI: $10.21608 /$ adjg.2021.46699.1305

Oral Medicine \& Surgical Sciences (Oral Medicine, Oral \& Maxillofacial Surgery, Oral Pathology, Oral Biology)

\section{KEYWORDS}

Implant stability, Tapered,

Bone density, Ostell.

\begin{abstract}
Purpose: This study was carried out to evaluate stability of tapered and cylindrical implants in partially edentulous patients. Materials and Methods: The current study was done on 14 implants that were alienated randomly into two groups: Group I: treated with tapered implant, Group II: treated with cylindrical implant. Results: Clinical results: Modified Gingival Index (MGI) revealed a non-significant statistically difference on comparing results of 3 months and 6 months postoperatively ( $p=0.254$ at 3 months, p=0.606 at 6 months). Modified Plaque Index (MPI) revealed $a$ non-significant statistically difference on comparing results of 3 months and 6 months postoperatively $(\mathrm{p}=0.298)$. Probing Depth(PD) revealed a non- significant statistically difference on comparing results of 3 months and 6 months postoperatively ( $\mathrm{p}=1$ at 3 months, $\mathrm{p}=0.591$ at 6 months). Stability: the mean value increased by time from baseline to after 6 months in Group I $(61.57 \pm 6.4$ to $71.57 \pm 6.08)$, however, the mean value increased from $63.14 \pm 7.17$ to $74.57 \pm 5.53$ in Group II. Implant stability revealed non- significant statistically differences for $\mathrm{p}$-values $(P 0.05)$. Radiographic results: Bone Density (BD):The statistical analysis between the two groups in the mean percent change in bone density revealed a non-significant statistically difference between the 6 months results. It was $1.88 \pm 1.37 \%$ for the first group and $11.54 \pm 15.63 \%$ for the second group $(p=0.20)$.Conclusions: Conical and cylindrical implants have comparable biological effects during the healing process. The properties of the bone site can influence the stability of the implant.
\end{abstract}

- Paper extracted from Master thesis titled 'Evaluation of Dental Implant Stability: A comparative Study of Tapered vs Cylindrical Implants

1. Dentist at Ministry of Electricity, Egypt.

2. Professor of Oral Medicine, Periodontology, Diagnosis and Radiology Faculty of Dental Medicine for Girls Al-Azhar University, Cairo, Egypt.

3. Associate Professor, Department of Oral Medicine, Periodontology, Diagnosis and Radiology, Faculty of Dental Medicine for Girls Al-Azhar University, Cairo, Egypt.

* Corresponding author email: eng_welaa2009@yahoo.com 


\section{INTRODUCTION}

Osseointegration is the key to the success of an implant that differs as a straight bone port for an implantation that can provide a basis for the maintenance of prostheses. It is also a measure of the implant stability, which takes place in two stages, primary and secondary. The stability of the implant is an essential characteristic of osseointegration without it, long-term achievement cannot be achieved ${ }^{(1)}$.

The design topographies of the implant include: macro design and micro design features. Macro design topographies include thread field, thread geometry, thread depth and thickness, thread design, and the graft crestal module, while micro design essentially takes into account surface morphology and coverages. The macro design provides concentration on the relationship between osseointegration and machine-controlled features of the implant design and helps to know which graft to select depending on different experimental conditions. Microdesign topographies consist of examining the biotic part of the implantation strategy and its applications to the design of the host response and the existence of the graft. It influences the cell behavior on the apparent like binding, multiplication and variation of cells as well as the mineralization of the extracellular background on the transplant sides ${ }^{(2)}$.

Objective measurement of implant stability through multiple procedures could assist the clinician in the optimal management strategy, improve patient-to-patient maintenance outcomes for implant installation procedures, provide better case documentation, and support good communication confidence ${ }^{(3)}$. Different methods for assessing implant stability are classified into invasive and noninvasive $^{(3)}$

The RFA system provides clinically applicable information about the condition of the implant-bone junction at each stage after the graft position. It can be used as an additional factor in assessing deployment during implant behavior and follow-up. This technique processes the echo from a transducer lo- cated near grafts in relation to micromotion or displacement, which in turn is measured by bone compactness $^{(4)}$. In view of these, the present study was carried out to evaluate implant stability in partially edentulous patients which was a comparative study of tapered versus cylindrical dental implant.

\section{MATERIALS AND METHODS}

\section{Study design:}

This current study was a comparative study on 14 implants obtained from clinics of Oral Medicine, Periodontology, Diagnosis and Radiology Department, Faculty of Dental Medicine, Al- Azhar University (Girls branch), and approved by the Research Ethics Committee of Faculty of Dental Medicine, Al- Azhar University.

\section{Sample size:}

Sample size calculation achieved using http:// biomath.info/power according to the research ${ }^{(5)}$. A total sample size of 14 patients (7 in each of two groups) was sufficient to detect the difference. Total numbers of patients were divided randomly in to two groups.

Patients will be divided into two groups randomly:

Group I: 7 surgical sites were undergoing tapered implant placement and evaluated implant stability with Ostell.

Group II: 7 surgical sites were undergoing cylindrical implant placement and evaluated implant stability with Ostell.

\section{Preoperative assessment}

Clinical assessment: all patients undergo for visual examination and palpation of the entire oral mucosa and obtained full mouth scaling and root debridement followed by proper oral hygiene instruction. Patients should be free of any systemic disease. Type of bone at implant site should be D2 or D3. 
Radiographic assessment: Periapical x-ray was obtained to detect any pathological lesion in the interest area and to check proper implant position and its relation to opposing landmarks and adjacent structure. Computed Tomography (CT) was used to record bone height then width of area of interest to choose the suitable implant size (diameter and length) and to draw the implant future recipient site by using available data.

Surgical procedure: All surgical steps were carried out under strict aseptic conditions. Following local anaesthesia of surgical area, (mepavecaine with epinephrine 1:100.000), After testing anaesthesia a crestal cut was made using a \#15 operating cutting edge, followed by intra-sulcular incision around adjacent teeth (one tooth mesial and one distal) were made, then full-thickness mucoperiosteal flap was raised using mucoperiosteal elevator to expose the underlying bone. Osteotomy site preparation through sequential drilling, the operating system were followed the procedure designated by the implantation business surgical set, with reduced low speed $(1500 \mathrm{rpm})$ under copious internal irrigation with normal saline. All grafts were sited at the flat of the alveolar top by an insert twisting of $35 \mathrm{Ncm}$, drilling direction must be parallel to the adjacent teeth, parallelism can be checked by using parallel pin of the implant company. After a proper osteotomy site preparation, according to the group either tapered or cylindrical the implant was removed from its sterile vial then held using its fixture adapter, installed manually until there is reaching proper depth. The implants were positioned in the osteotomy site flushing it with the margin of the crest. The primary stability was assessed using Osstell for all implant by the situation of a smart peg into the graft, which is secured into the implantation and the usage of a transducer, which is held adjacent to and upright to the Smart Peg without really creating touching.(Figure 1) A restorative cap (gingival former) was applied for all implantations by hand torque. The mucoperiosteal folds were adjusted around the graft neck to permit non-submerged curing and were stitch up with silk stitches stitching was done with interrupted sutures using non resorbable sutures (3/0 black silk). Suture removal was done 14 days postoperatively.

Three months after surgery, the healing cap was removed then assessed the secondary stability using Osstell, then placement the abutment supplied by the implant system company. After that proper adjustment of the abutment and direct impression was made for fixed appliance construction by heavy and light rubber base impression material. The final crown made of porcelin fused to metal cemented on abutment.

Post-operative care and instructions: All patients were instructed to apply of extra oral ice packs (10-20 minutes) over the site of implant in the day of surgery to avoid hematoma formation, and to prescribe antibiotic (Megamox 1g twice/day for 5 days), analgesic (Biprufenid 400mg as needed) and to wash with $0.12 \%$ chlorhexidine gluconate oral wash two times daily after surgery.

Clinical parameters: The clinical parameters of this study were evaluated using; Modified Plaque Index (MPI), Modified Gingival Index (MGI) and Probing Depth (PD) at 1month (after fixture placement), 3 months (installing) and 6 months (3 months after installing) intervals. A periodontal probe was used for clinical measurements.

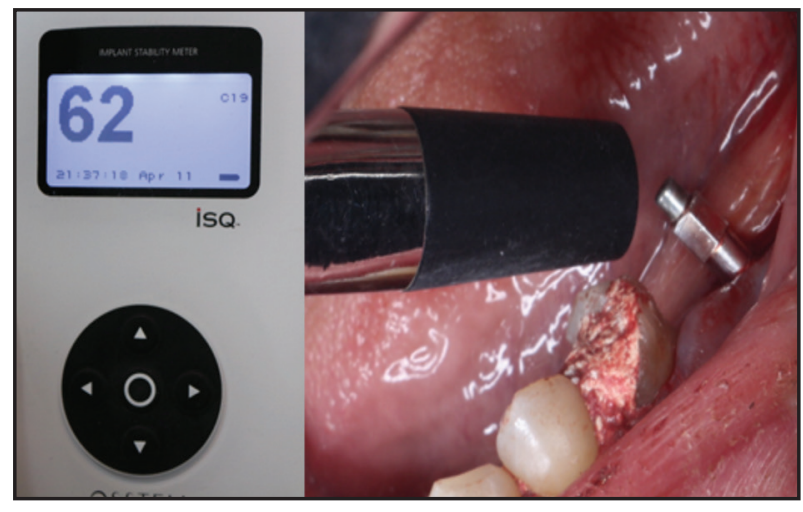

Figure (1): Osstel recording secondary stability reading 


\section{Statistical analysis:}

Numerical data were the summarized using means and standard deviations. Comparisons between 2 groups were done using the independent t-test. All p- values are two sided.P values $\leq 0.05$ were considered significant.

\section{RESULTS}

\section{Clinical results}

\section{Modified Gingival Index (MGI):}

Group I(the surgical site was received tapered implant): The statistical analysis of results of the mean Modified Gingival Index (MGI) showed no significant difference between values $(\mathrm{p}=0.097)$ throughout the study period (baseline $0 \pm 0,3$ months $0.14 \pm 0.38$ and 6 months $0.43 \pm 0.53$ ).

Group II (the surgical site was received cylindrical implant): The statistical analysis of results of the mean Modified Gingival Index (MGI) showed no significant difference between values $(\mathrm{p}=0.039)$ throughout the study period (baseline $0 \pm 0,3$ months $0.34 \pm 0.53$ and 6 months $0.57 \pm 0.53$ ). A non-significant statistically difference in gingival index was observed on comparing results of 3 months and 6 months postoperatively $(\mathrm{p}=0.254$ at 3 months, $\mathrm{p}=0.606$ at 6 months).

\section{Stability}

Group I:The mean value increased by time from $61.57 \pm 6.4$ at baseline to $71.57 \pm 6.08$ after 6 months . The difference by time was statistically significant $(\mathrm{p}=0.00)$.

Group II: Regarding stability within group II throughout the study period, there was a highly significant difference between baseline and 6 months readings (baseline 63.14 $\pm 7.17,6$ months $74.57 \pm 5.53)$.
However, Group II recorded a higher mean value $(63.14 \pm 7.17)$ at baseline, $(74.57 \pm 5.53)$ after 6 months compared to Group I which recorded (61.57 \pm 6.4$)$ at baseline, (71.57 \pm 6.08$)$ after 6 months, the results of mean revealed the difference between groups was not statistically significant $(p=0.673)$.

Group II recorded a higher mean value of difference by time $(11.43 \pm 3.1)$ compared to Group I $(10.00 \pm 3.11)$, the results revealed the difference between groups was not statistically significant $(\mathrm{p}=0.404)$. Group II recorded a higher mean value of percent change by time (18.72 \pm 7.36$)$ compared to Group I (16.56 \pm 5.87$)$. The statistical analysis between the two groups regarding the mean percent change in stability showed that there was a statistically significant difference between baseline, 3 months and 6 months of both groups, the results revealed the difference between groups was not statistically significant $(\mathrm{p}=0.701)$

\section{Radiographic results}

\section{Bone Density (BD):}

The bone density measurements within group I throughout the study period showed a statistically significant increase in measurement between baseline and the 6 months readings (baseline $356.63 \pm 180.84$ and it was reached at 6 months $361.58 \pm 180.58)$ with $4.95 \pm 3.00$ increase.$(p=0.010)$

Regarding bone density measurements within group II throughout the study period showed a statistically significant increase in measurement between the baseline and 6 months (baseline 328.30 \pm 180.52 and 6 months $346.17 \pm 170.78$ ) with $17.87 \pm 12.83$ increase. $(p=0.019)$.The statistical analysis between the two groups in the mean percent change in bone density revealed a non-significant statistically difference between the 6 months results. It was $1.88 \pm 1.37 \%$ for the first group and $11.54 \pm 15.63 \%$ for the second group $(\mathrm{p}=0.20)$ 
Table (1) Changes in the mean MGI, stability and bone density in Group I\&II.

\begin{tabular}{|c|c|c|c|}
\hline & Group I & Group II & \multirow{2}{*}{$\mathbf{p}$} \\
\hline & Mean \pm SD & Mean \pm SD & \\
\hline \multicolumn{4}{|c|}{ Modified Gingival index (MGI) } \\
\hline Baseline & $0.00 \pm 0.00$ & $0.00 \pm 0.00$ & 1.000 \\
\hline After 6 months & $0.43 \pm 0.53$ & $0.57^{\mathrm{a}} \pm 0.53$ & 0.606 \\
\hline $\begin{array}{l}\text { Difference From } \\
\text { baseline to } 6 \text { months }\end{array}$ & $0.43 \pm 0.53$ & $0.57^{\mathrm{a}} \pm 0.53$ & 0.606 \\
\hline \multicolumn{4}{|l|}{ Stability } \\
\hline Baseline & $61.57 \pm 6.08$ & $74.57 \pm 5.53$ & 0.673 \\
\hline After 6 months & $71.57 \pm 6.08$ & $74.57 \pm 5.53$ & 0.353 \\
\hline $\begin{array}{l}\text { Difference From } \\
\text { baseline to } 6 \text { months }\end{array}$ & $10.00 \pm 3.11$ & $11.43 \pm 3.1$ & 0.404 \\
\hline \multicolumn{4}{|l|}{ Bone density } \\
\hline Baseline & $356.63 \pm 180.84$ & $328.30 \pm 180.52$ & 0.791 \\
\hline After 6 months & $361.58 \pm 180.58$ & $346.17 \pm 170.78$ & 0.882 \\
\hline $\begin{array}{l}\text { Difference From } \\
\text { baseline to } 6 \text { months }\end{array}$ & $4.95 \pm 3.00$ & $17.87 \pm 12.83$ & $0.024 *$ \\
\hline
\end{tabular}

* Significance difference, $P$ ( $p$-value):probability level

\section{DISCUSSION}

The immobility of the implantation plays an important role for effective osseointegration, which has been recognized as a physical and efficient connection between the jawbone sides of the loadbearing implantation. Primary immobility (in the situation) and secondary immobility (improving osseointegration in the restorative procedure below) are two major factors in implant performance ${ }^{(6)}$.

The immobility of the initial implantation has long been measured as a necessary predictor for effective osseointegration ${ }^{(7)}$. The study had found a high ratio of graft abortions (32\%) to implants showing insufficient initial strength ${ }^{(8)}$. Therefore, it seems to have a great initial strength and reduces the risk of micro-movements and antagonistic matter reactions, such as the formation of fibrous matter at the bone graft border through healing and payment in installments. It has been suggested that primary implant strength is affected by the quality and quantity of the Jaw bone, the graft scheme, and the method of operation used ${ }^{(9)}$.

The results of this study showed that conical and cylindrical implantations in the posterior area of the Jaw bone showed comparable biomechanical (PS and SS). However, compared to conical implants, cylindrical implants showed higher stability values over time. The difference between the implants was not statistically significant. A clarification to our results could be the drilling order accepted in our e x perimental sample. The placement of the two dental implants firmly followed the installment method proposed by the designer and bypassed any approach to stimulate an underdeveloped jawbone position, without compaction of the bone bed. Conical, root-shaped implants created a tight connection between the osteotomy side and the graft surface. The close-fitting contact, which offers a high level of basic mobility but has local jawbone necrosis, closes the implantation surface before the jawbone apposition guarantees its biomechanical fixation ${ }^{(10)}$.

Cylindrical implants with a matching wall are likely to be less stable during transplantation, but quickly gain stability due to the initial development of a woven jawbone after the clotting hole of the lifeblood between the implantation and the osteotomy wall ${ }^{(10)}$. Like the main implant strength for conical and cylindrical tooth transplants, it has also been described in an in-vitro study ${ }^{(11)}$. In agreement with the current results, the authors found significantly advanced ISQ values in the cylindrical implants ${ }^{(12)}$. In other study, cylindrical implants showed an extended resonance frequency analysis (RFA), so that the performance rate for conical implants was $86 \%$ and for parallel-walled implants $100 \%{ }^{(12)}$.

In con trast to the results of the current study, conical implants in an animal model had higher ISQ value s compared to re gular Bränemark implants 
(cylindrical) ${ }^{(13)}$.Similar results were obtained from another study on human cadavers ${ }^{(14)}$. An animal study comparing different implant designs found that tapered implants showed significantly greater stability than other straight cylindrical implants. Anoth e $r$ study suggest e $d$ that tapered implants exert additional late $\mathrm{ral}$ compressive force on the bony walls next to the implantation ${ }^{(5)}$. Therefore, in areas with insufficient bone quality and quantity, the use of tapered implants is suggested to achieve improved primary stability ${ }^{(5)}$.

The improvement of scientific, preferably noninvasive, examination instruments with great sensitivity and reproducibility to detect initial variations in graft strength during the installation of dental implants in tissue has been given the proliferation and growing popularity of implants placed directly in extraction holes and / or initial loading processes. In this detail, RFA is a clinical technique that can be used to measurably as sess the strength of the primary implant in order to: Detect implants with insufficient strength and take action to advance them. Select the healing method (one level / two levels). Select whether direct / delayed charging should be suitable. Choose the amount of healing before loading (normal or extended healing) ${ }^{(15)}$.

The implants of each method would approach with a period, a similar level of strength, which appears to be an implant stability quotient of 6575 for Branemark category implants and an implant stab i lity quotient of 55-65 for Straumann-type implants. In the present study, the values ranged from 60 to 70. It seems reasonable to assume that this degree of stability indicates a safe level of stability at any point in time during the life of an implant. A quotient value for implantation stability below 55 (Branemark) or 45 (Straumann) should be viewed as a threatening sign and methods for increasing implantation stability should be measured. Primary stability can be improved by changing the surgical technique and choosing a wider, longer, or tapered implant. For example, the use of thinner drills and wider and tapered implants increases the strength of the primary implant ${ }^{(3)}$.
In the present study, most cases show Jaw bone qualities of type II and III. Regardless of the type of Jaw bone, a significant decrease in ISQ values can be observed after 4 weeks, which steadily improves postoperatively. This decrease in ISQ records can be partially explained by the variations that occur at the interface between implantation and bone during the primary healing stage. The main strength of a dental implant, which has been retained throughout the surgical interventions, is purely mechanical and is due to the fixation of a press-fit arrangement in a bony osteotomy. In the first weeks of the curation, bone modeling and remodeling take place around the i mplantation s urface. This stage, with the development of lamellar bone from woven bone, can lead to a reduction in primary bone interaction ${ }^{(16)}$.

\section{REFERENCES}

1. Goutam M, Chandu GS, Mishra SK, Singh M, Tomar BS. Factors affecting osseointegration. J Orofac Res. 2013,3:197-201

2. Gurzawska K. Nanocoating of titanium implant surfaces with organic molecules Polysaccharides including glycosaminoglycans. J Biomed Nanotechnol. 2012;8: 1012-24

3. Muhamad A, Georges C, Mustafa M,Abdulgani A. Implant stability: methods and recent advances. J Dent Med Sci. 2017;16:13-23

4. Prithviraj DR,Sounder K, Shruthi DP, Shruti S, Mamatha N. A review on implant failures. J Appl Dent Med Sci. 2016; 2 : $184-89$

5. Waechter J, Madruga MM, Schinestck AR, Foat F. Comparison between tapered and cylindrical implants in posterior regions of mandible. Clin Implant Dent Relat Res. 2017;19: 733-41

6. Liu Y, Rath B, Tingart M, Eschweiler J. Role of implants surface modification in osseointegration. J Biomed Mater Res. 2020;108: 470-484

7. KayhaZO, Kazazoglu E. An overview of implant stability measurement. Mod App Dent O H. 2018; 2: 210-13

8. Elias CN, RochaFA, NascimentoAL, CoelhoPG.Influence of implant shape, surface morphology, surgical technique and bone quality on the primary stability of dental implants. J Mech Behav Biomed Mater. 2012; 16:169-180.

9. Wilson TG, Miller RJ, Trushkowsky R, Dard M. Tapered implants in dentistry. Adv Dent Res. 2016; 28:4-9 
10. Alejandra EB, Gloria MS, Maria GA, Marianela GE, Jesus RP. Diagnosis and clinical conditions for the placement of immediate implants in the posterior area. Int J Appl Dent Sci. 2019; 5:434-37

11. Gehrke S, Frugis VL, Shibli JA, Fernandez MP. Influence of implant design in the load transfer surrounding long and short length implants. Open Dent J. 2016; 10: 522-30

12. Andersson P, Sennerby L, Pagliani L, Volpe S, Sahlin H. Factors influencing resonance frequency analysis measurement. Int J Dent. 2019; 4:1-10.
13. Pozzi A, Mura P. Immediate loading of conical connection implants. Int. J. Oral Maxillofac. Impl. 2016; 31: 142-152.

14. Wancket LM. Animal models for evaluation of bone implants and devices. Adv Dent Res. 2015; 52:842-50

15. KanthKM,Swamy DN, Mohan TK, SwarnaC, Sanivarapu S, Pasupuleti M. Determination of implant stability by resonance frequency analysis device during early healing period. J NTR Univ Sci. 2014; 3:169-175

16. Liu P, Pan C, Tseng Y, Wu C, Chang H. Effects of cortical bone thickness and trabecular bone density on primary stability of orthodontic mini-implants. J Dent Sci. 2019; 14: 383-88 